рабочих мест, соответствующих образованию населения, доля высокооплачиваемых мест - пока еще различаются по регионам страны более чем вдвое [6]. Саратовская область пока «проигрывает» в конкуренции за человеческие ресурсы и их качество (отток из области трудоспособного населения с высшем образованием) многим регионам страны. Дальнейшие темпы сокращения численности населения области будут зависеть от социально-экономического развития нашего региона в ближайшие годы, возможности «стягивать» человеческие ресурсы своей внутренней периферии и удерживать собственное население, привлекать высококвалифицированных мигрантов из других регионов страны, рационального использования квалификации и трудовых навыков населения.

\section{Библиографический список}

1. Демографический ежегодник Саратовской области. 2008г: Стат. сб. Саратов, 2009. 180с.

2. Рыбаковский Л. Оценка уровня демографического неблагополучия регионов России: социальные и экономические последствия // Междунар. экономика. 2008. №3. С. 54. 3. Демографический ежегодник Саратовской области. 2006г: Стат. сб. Саратов, 2007. 186c.

4. Пилясов А., Колесникова О. Оценка творческого потенциала Российских региональных сообществ // Вопросы экономики. 2008. № 9. С.50-69.

5. http://www.raexpert.ru/ratings/regions/2009 (дата обращения: 07. 02. 2010)

6. Зубаревич $H$. Кто выиграет конкуренцию за человеческие ресурсы? // Рос. экспертное обозрение. 2008. №1 (24). C.12-16.

\title{
ГЕОИНФОРМАЦИОННОЕ КАРТОГРАФИРОВАНИЕ ГЕОЭКОЛОГИЧЕСКИХ РИСКОВ ЭКСПЛУАТАЦИИ НЕФТЯНЫХ МЕСТОРОЖДЕНИЙ (на примере Саратовской области)
}

\section{А.В. Молочко}

Саратовский государственный университет, кафедра геоморфологии и геоэкологии E-mail: farik26@yandex.ru

В статье рассмотрены понятия риска в целом, а также геоэкологического риска как одного из проявлений риска эксплуатации нефтяных месторождений в разрезе региональных особенностей территории Саратовской области. Раскрывается схема оценки геоэкологического риска с упором на картографический рисканализ нефтяных месторождений с применением геоинформационных технологий.

Ключевые слова: риск, геоэкологический риск, факторы геоэкологического риска, риск-анализ, нефтяная промышленность, картографический метод риск-анализа, ГИС, картографирование риска, Саратовская область.

Geoecological Risks' geoinformational Mapping of oil-fields Exploitation (Saratov Region as an Example)

\section{A.V. Molochko}

The article represents general concept of the «risk» and concept of geoecological risk as a one of oil-fields' risk exploitation manifestation within the regional features of Saratov region. Also the general chart of risk estimation with emphasis on cartographical risk-analysis of oilfields with application of GIS is disclosed in the article.

Key words: risk, geoecological risk, geoecological risk factors, riskanalysis, oil industry, cartographic method of risk-analysis, GIS, risk mappinig, Saratov region.

Коллективы лаборатории геоинформатики и тематического картографирования и лаборатории

урбоэкологии Саратовского государственного университета им. Н.Г. Чернышевского с 2003 г. на договорных условиях внедряют ГИС-технологии в практику работы ряда служб и подразделений OAO «Саратовнефтегаз». Основным направлением работы в эти годы являлось создание экологически ориентированных геоинформационных систем нефтяного месторождения «ГИС-нефтепромысел» и трасс напорных трубопроводов («ГИС-трубопровод») как универсального средства сбора, обработки и представления информации об экологической обстановке и инженерном обустройстве на нефтепромыслах, трубопроводах и прилегающих к ним территориях [1]. Последнее время коллективами лабораторий и специалистами ОАО «Саратовнефтегаз» особое внимание уделяется проблеме геоэкологического риска эксплуатации нефтегазовых месторождений предприятия.

Понятие «риск» прочно вошло в обиход современного общества. В любой сфере человеческой деятельности можно встретить термин «риск» и близкие ему понятия - «опасность», «ущерб», «рисковая ситуация» и т.п. До сих пор среди исследователей нет общего мнения, ставить ли знак равенства между этими и подобными им терминами. По ГОСТу риск - это вероятность события и его последствия, по руководящим документам - сочетание частоты и последствий определенного опасного события, для ряда ученых - неопределенность предполагаемых событий, которые чаще всего приводят к негативным 
последствиям [2 - 5]. Еще сложнее обстоит дело с трактовкой риска геоэкологического. Одни исследователи определяют его как частный вариант экологического риска, другие допускают наличие геоэкологических рисков только со стороны геологической составляющей природной среды [6]. На наш взгляд, геоэкологический риск - риск нарушения среды обитания человека, то, что влияет на ее структуру, сохранность, изменчивость и восприимчивость.

Различного рода риски способны привести как к материальным, техническим, так и человеческим потерям. Поэтому изучение риска, поиск путей его снижения и предотвращения - задача исключительно важная.

Совокупность методов, позволяющих выявить возможные опасности, оценить риск, выработать систему рекомендаций и методик по управлению и снижению последствий каких-либо вызывающих угрозу процессов и явлений, представляет собой инструментарий риск-анализа [7].

Если говорить о геоэкологических рисках, то схему риск-анализа можно разложить на составные части, включающие в себя следующие этапы (рис. 1): риска;

1) определение факторов геоэкологического

2) выявление источников и реципиентов риска;

3) выбор методов оценки риска;

4) построение на основе выбранной методики прогнозов дальнейшего развития процессов, создание сценариев.

5) разработку рекомендаций по снижению риска и предотвращению последствий рисковых ситуаций, мониторинговых мер по слежению за опасными с точки зрения цозникновения геоэкологического риска объектами и явлениями.

В целом факторы геоэкологического риска можно подразделить на три большие группы: природные, техногенные и социальные (см. рис. 1). Обычно для промышленного производства данные группы факторов работают в комплексе, где трудно оценить значимость какого-то конкретного параметра.

Следует отметить, что одни и те же факторы могут играть как отрицательную (усиливать риск), так и положительную (уменьшать риск) роль в системе существования рисков. Это зависит от рассматриваемых объектов, процессов или явлений, мест их локализации, условий протекания и др. Тем не мение существуют такие факторы, которые однозначно усиливают геоэкологический риск: расположение рассматриваемых объектов в зонах сезонного подтопления, несомненно, увеличивает риск их эксплуатации; обслуживание таких объектов социально не защищенным персоналом ведет к пресловутому «человеческому фактору»; близость объектов к потенциально взрывоопасным предприятиям тоже может рассматриваться исключительно как отрицательный фактор $[8,9]$.
Скрупулезный анализ факторов дает возможность перейти к собственно оценке геоэкологического риска. Здесь возможно использование самых разнообразных количественных и качественных методов, которые подразделяются на инженерные, модельные, экспертные, социологические и т.д. (см. рис. 1.) [10].

Отдельной группой среди методов анализа геоэкологических рисков стоят картографические методы. Они позволяют осуществлять визуализацию данных, полученных количественными методами риск-анализа, экспертными оценками либо качественными «древами отказов», создавать математико-картографические модели, отражающие динамику или взаимосвязь процессов и явлений, находить оптимально решение по предотвращению рисков.

Картографический метод позволяет не только составлять инвентаризационные и оценочные карты рисков, моделировать происходящие процессы, но и давать прогнозы развития ситуации, давать рекомендации на основе этих прогнозов, давать нормативные документы, оптимизирующие производственную деятельность.

Подобная схема риск-анализа работает и в нефтяной отрасли. Множество методик количественной оценки и анализа промышленных аварий и риска на нефтяных месторождениях, трубопроводах, объектах хранения и переработки углеводородного сырья нашли свое применение на крупнейших нефтяных предприятиях Российской Федерации. Однако картографический риск-анализ месторождений и объектов их обустройства распространен не столь широко.

При выполнении работ по созданию баз данных и картографических материалов на нефтегазовые месторождения ОАО «Саратовнефтегаз» мы столкнулись с тем, что большая часть информации, а также результаты разнообразного анализа были сосредоточены в таблицах, схемах и текстах [1]. При этом вся информация была между собой мало связана. Сложилась достаточно парадоксальная ситуация, когда данных об объекте много, а привести их к общему знаменателю, выработать на их основе необходимые рекомендации далеко не всегда получается просто из-за отсутствия пространственного восприятия происходящих процессов на рассматриваемой территории. Для оценки геоэкологического состояния территории, геоэкологического риска эксплуатации нефтяного месторождения, трубопровода или объектов хранения и переработки нефти это недопустимо.

Создаваемые нами для месторождений и трубопроводов геоинформационные системы снимали эту проблему. Известно, что географические информационные системы как уникальный продукт на стыке информатики, географии, картографии, фотограмметрии, математической статистики, дизайна, топографии и других научных дисциплин существенно упрощают и упорядочивают сбор и хранение информации, 


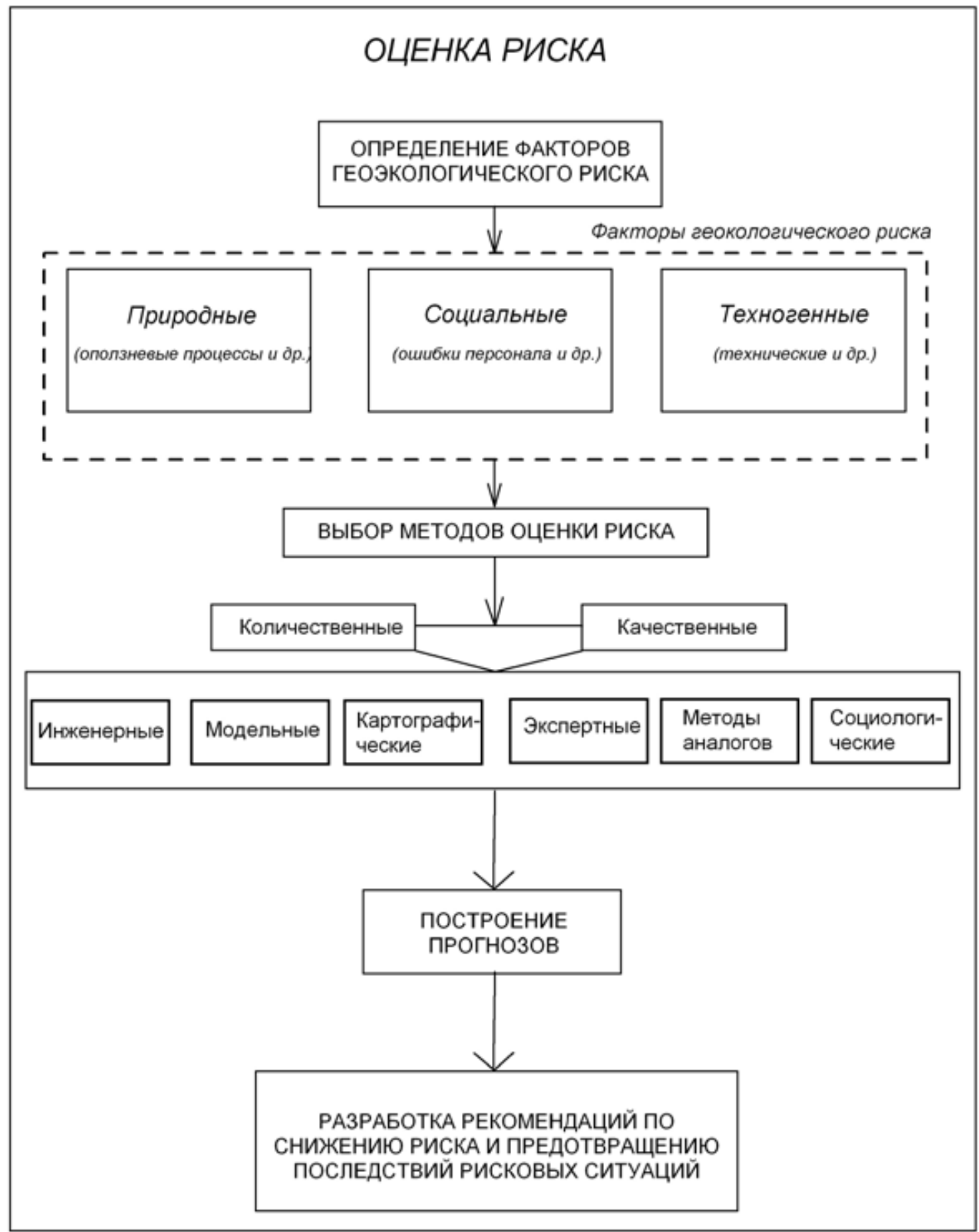

Рис. 1. Схема риск-анализа

позволяют проводить полный пространственный анализ данных при решении общих и прикладных задач, таких, например, как разведка, сопоставление данных бурения по скважинам, управление арендой, контроль производства, прогноз нефте- и газоносности района, выбор и слежение за работой оборудования, природный мониторинг, составление общих и специализированных карт, моделирование процессов и явлений, сопрово- ждающих функционирование нефтяной отрасли, и многое другое.

В результате выполнения проектов за эти годы нами были созданы обширные базы данных:

- картографических материалов территории объектов ОАО «Саратовнефтегаз», актуализированных по результатам обработки данных аэро- и космического зондирования и полевых съемочных работ; 
- геоэкологического обследования территорий: содержание микроэлементов в почвах, нефтяные утечки, эрозионная расчлененность, подтопление территории и пр.;

- отраслевой информации предприятия и т.д.

Таким образом, в результате работ был создан инструментарий для моделирования опасных геоэкологических процессов, организации геоэкологического мониторинга, разработки управленческих решений, которые могут оказывать существенное влияние на принятие нормативноправовых документов в области природоохранной деятельности предприятия.

В качестве дальнейшего развития проекта предложены разработка и внедрение в существующие геоинформационные системы «ГИС- нефтепромысел» подблока «Управление рисками» (рис. 2)

Основными особенностями предлагаемой интегрированной системы являются:

- широкое использование аэро- и космических снимков высокого и сверхвысокого разрешения на территорию нефтепромыслов на основе отработанных алгоритмов их геометрической нормализации и географической привязки, данных глобального позиционирования, в виде координат точек обследования модельных участков, а также территорий исследования, материалов фото- и видеофиксации, отражающих современное геоэкологическое состояние изучаемой территории;

- использование различных приемов математико-картографического моделирования для

\section{ПОДБЛОК УПРАВЛЕНИЯ РИСКАМИ в "ГИС - НЕФТЕПРОМЫСЕЛ"}

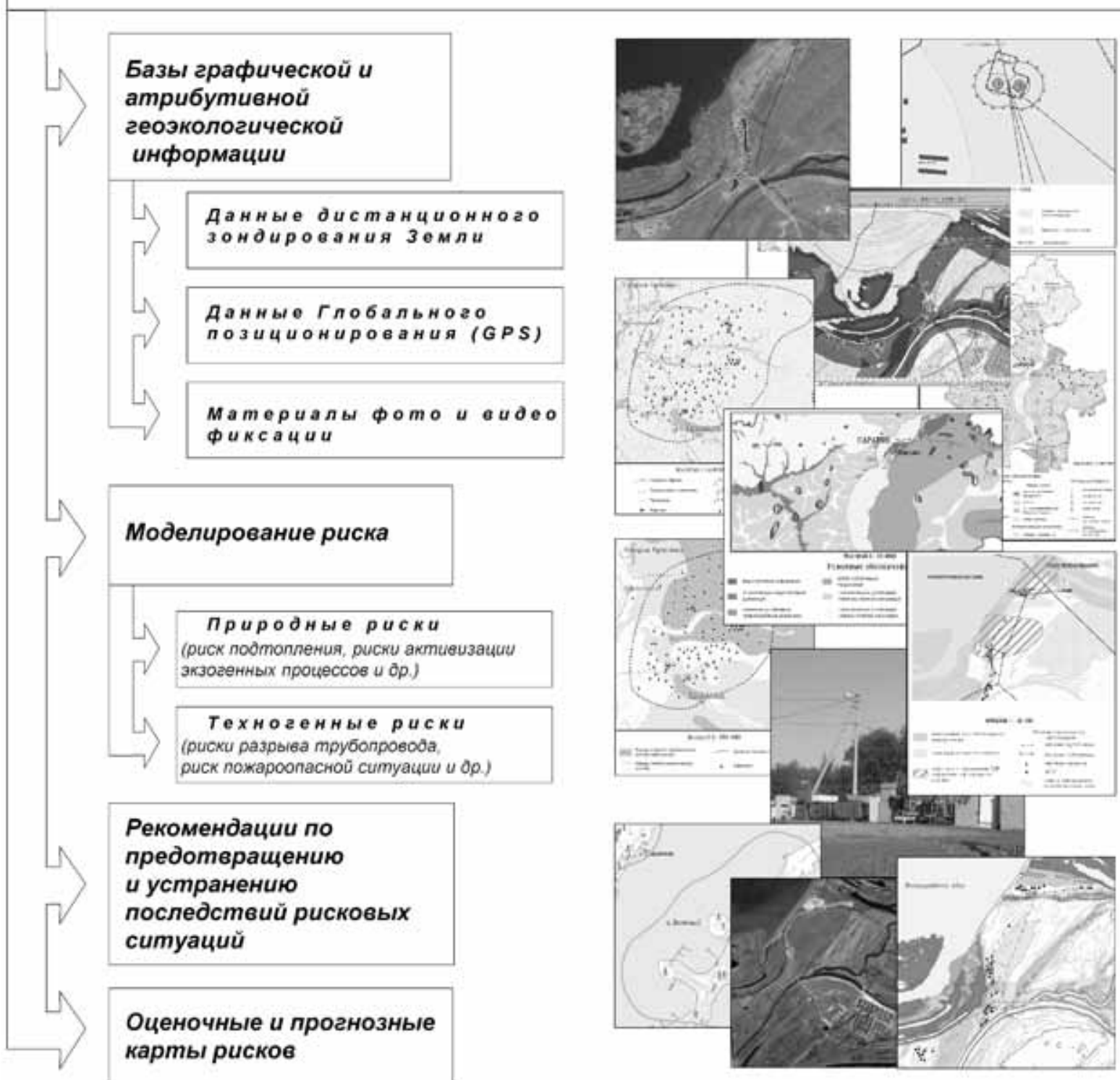

Рис. 2. Структура подблока «Управление рисками» 
создания карт оценки природных и техногенных рисков эксплуатации месторождений;

- организация мониторинга объектов и факторов риска, построение прогнозов развития рисковых ситуаций и разработка рекомендаций по их предотвращению и устранению.

Следует отметить, что одной из важнейших составляющих работ при оценке риска эксплуатации нефтяных месторождений являются изучение региональных и локальных особенностей проявления рисковых ситуаций, оценка факторов, увеличивающих и снижающих этот риск. Для каждого месторождения есть ряд своих особенностей, однако в целом для Саратовской области среди основных рисковых ситуаций можно выделить следующие [11]:

1. Гидрологические и гидрогеологические особенности:

- высокий показатель густоты речной сети и ее неравномерное распространение по территории области (высокий показатель для правобережья и низкий - для левобережья) - влияет на возможные проявления подтопления, а также активизацию экзогенных процессов, что, в свою очередь, воздействует на объекты инфраструктуры нефтепромысла, а также объекты транспорта нефти и нефтепродуктов;

- подтопление территории вследствие сезонного подъема уровня поверхностных и грунтовых вод средних и малых рек - вызывает аварийные и чрезвычайные ситуации, поражающие многие элементы инфраструктуры, в особенности если кустовые площадки и другие опасные производственные объекты расположены в пойме и на низких террасах;

- затопление территории в результате экстремального подъема уровня крупных и средних рек в период половодья, а также резкое увеличение уровня Волгоградского и Саратовского водохранилищ, возможное в результате нарушения целостности гидротехнических сооружений плотин ГЭС, а также вследствие ошибок, нарушений технического и технологического регламента их работы - способны привести не только к похожим с подтоплением воздействиям на инфраструктуру нефтепромысла, но и в ряде случаев к частичному или полному разрушению как буровых установок, так и всей инфраструктуры, включая трубопроводы, дороги и нефтесборные пункты;

- ледоход и зажоры в местах водных переходов нефтепроводов, а также серьезные наледи на трубопроводах, объектах обслуживания и функционирования нефтепромысла;

- колебания уровня грунтовых вод, способные привести к подтоплению территории нефтепромысла и трассы прохождения нефтепровода, а также степень их минерализации как фактор, способствующий усилению коррозии металлических элементов объектов обслуживания и трубопроводов;
- абразионная деятельность Волгоградского и Саратовского водохранилищ, приводящая к активизации оползневых и осыпных процессов - серьезный фактор геоэкологического риска для нефтепромыслов, примыкающих к прибрежным районам, а также объектов инфраструктуры, поскольку может привести к аварийным ситуациям, угрожающим линейным сооружениям (дороги, трубопроводы) и площадным элементам инфраструктуры - промплощадкам и резервуарным паркам, дожимным насосным станциям, центральным пунктам сбора нефти, цехам подготовки и перекачки нефти и др.

2. Геологические и почвенные особенности территории:

- один из наиболее высоких уровней вертикального расчленения рельефа, характерный для отрогов Приволжской возвышенности, проявляющийся в высокой густоте овражной сети, способный оказать воздействие на нефтепромысел и инфраструктуру в виде разрывов трубопроводов и аварийным ситуациям на них, нарушений целостности объектов обслуживания нефтепромысла, а также самих буровых;

- плоскостной смыв со склонов преимущественно Приволжской возвышенности - возможная причина аварий и нарушений в функционировании трубопроводов и нефтепромыслов;

- оползневые процессы, приуроченные к правобережью области, долинам крупных и средних рек, отличающихся глубоким положением долин и русел способны привести к разрушению инфраструктуры и элементов функционирования нефтепромысла, так же как и другие экзогенные динамические процессы;

- наличие линиаментов разного порядка в пределах территории и, как следствие, развитие вдоль данных разломов геопатогенных зон - оказывают существенное воздействие на нефтепромысел и объекты его инфраструктуры вследствие активизации вдоль разломов экзодинамических процессов;

- повсеместное распространение осадочных пород легкого гранулометрического состава как результат трансгрессий Каспийского моря и оледенений - способно привести к существенному увеличению площади распространения загрязнения при аварийных ситуациях на нефтепромысле и трубопроводах, а также усилить воздействие грунтовых вод на поверхностные воды при кратковременных или постоянных подъемах их уровня, что может оказать то же воздействие на нефтепромысел и его инфраструктуру, что и в случае с подтоплением или затоплением;

- особенности распространения засоленных почв, а также наличие линз солонцов и солончаков - способствуют усилению коррозионной агрессивности почвенной среды на металлические элементы трубопроводов и строений нефтепромысла и могут привести к нарушению их целостности и риску аварийных ситуаций; 
- практически повсеместно высокий показатель нефтеемкости почвогрунтов, усиливающий площадь распространения возможного загрязнения при авариях с разливом и фонтанированием нефти и нефтпродуктов.

3. Атмосферные особенности территории:

- практически полное отсутствие безветрия на территории области - также может затруднить нормальный режим работы на нефтепромыслах. Сильные и частые ветры производят большую разрушительную работу на откосах дорог, обвалование кустов скважин, амбаров и др. Кроме того, они могут повредить наружные технологические установки, линии и опоры электропередач и т.д. Обрыв линий электропередач и прекращение подачи электроэнергии на объекты способны вызвать временную приостановку всего производственного цикла на нефтепромыслах, привести к технологическим поломкам и, как следствие, к аварийным ситуациям;

- сильные метелевые и ливневые явления, связанные с преобладанием западного переноса воздушных масс, а также сильной циклонической активностью прилегающих территорий - могут привести к затрудненному проезду к местам возможным аварий, к разрушению конструкций под действием тяжести снега или затоплению в следствие сильных ливней;

- явления, связанные с обледенением и гололедом, способствующие аварийным ситуациям, связанным с нарушением электроснабжения объектов обслуживая и функционирования нефтепромысла, а также увеличению времени реагирования аварийных групп при критических ситуациях за счет затрудненного доступа к объекту аварии;

- засухи и, как следствие, степные и лесные пожары, способные вызвать воспламенение на объектах функционирования нефтепромысла, а также нанести вред инфраструктуре обслуживания.

Уже к настоящему времени использование подблока «Управление рисками» геоинформационных систем нефтепромыслов ОАО «Саратовнефтегаз» позволило построить ряд карт из предложенного выше перечня возможных рисковых ситуаций: уровней геоэкологического риска для Урицкого нефтяного месторождения; зонирования территории о-ва Зеленый Соколовогорского нефтепромысла по степени риска для туристскорекреационной зоны; подтопления территории Белокаменного нефтегазового месторождения и т.д. Их создание - первый шаг в разработке геоинформационой системы риск-анализа эксплуатации нефтяных месторождений Саратовской области.

\section{Библиографический список}

1. Макаров В.3, Чумаченко А.Н., Данилов В.А и др. Применение ГИС-технологий при оценке факторов природного риска на нефтяных месторождениях Нижнего Поволжья // Проблемы региональной экологии. 2004. № 3. С. 89-99.

2. Кочуров Б.И., Миронюк С.Г. Подходы к определению и классификации экологического риска // География и природные ресурсы. 1993. № 4. С. 22-27.

3. Ревзон А.Л., Камылиев А.П., Крафт Я.С. Предупреждение природно-техногенных аварий при строительстве // Экология и промышленность России. 2000. Апрель. C. $42-48$.

4. ГОСТ Р 51901-2002. Управление надежностью. Анализ риска технологических систем. М., 2002. 26 с.

5. РД 08-120-96. Методические указания по проведению анализа риска опасных промышленных объектов. М., 1996. $18 \mathrm{c}$.

6. Абалаков А.Д. Экологическая геология. Иркутск, 2007. $267 \mathrm{c}$.

7. Ваганов П.А., Манг-Сунг Им. Экологические риски. СПб., 2001. 152 c.

8. Молочко А.В. Геоэкологическая оценка природных факторов риска эксплуатации нефтегазовых месторождений средствами геоинформационных систем (на примере Белокаменного месторождения) // Геоинформационное картографирование в регионах России: Материалы Всерос. науч.-практ. конф. (Воронеж, 2 декабря 2009 г.) / Воронеж. гос. ун-т. Воронеж, 2009. С. 134-138.

9. Макаров В.З., Молочко А.В., Фролов В.А. и др. Моделирование факторов пожароопасной ситуации на нефтесборных пунктах с использованием геоинформационных технологий // Изв. Сарат. ун-та. Новая серия. 2009. Т. 9. Сер. Науки о Земле, вып. 1. С. 32-38.

10. Количественная оценка риска химических аварий / Под ред. В.М. Колодкина. Ижевск, 2001. 228 с.

11. Саратовский ЦГМС, Центр мониторинга и прогнозирования чрезвычайных ситуаций МЧС Саратовской области. URL: http://64.mchs.gov.ru/forecasts/index.php?ID=1916 (дата обращения: 29.03.2010). 